\title{
Epigenetic control of effectors in plant pathogens
}

\author{
Mark Gijzen ${ }^{1,2}$ *, Chelsea Ishmael ${ }^{1,2}$ and Sirjana D. Shrestha ${ }^{1,2}$ \\ ${ }^{1}$ Agriculture and Agri-Food Canada, London, ON, Canada \\ 2 Department of Biology, University of Western Ontario, London, ON, Canada
}

\section{Edited by:}

Yuhai Cui, Agriculture and Agri-Food

Canada, Canada

\section{Reviewed by:}

Guus Bakkeren, Agriculture and

Agri-Food Canada, Canada

Barbara Valent, Kansas State

University, USA

${ }^{*}$ Correspondence:

Mark Giizen, Agriculture and Agri-Food

Canada, 1391 Sandford Street

London, ON N5V 4T3, Canada

e-mail:mark.gijzen@agr.gc.ca
Plant pathogens display impressive versatility in adapting to host immune systems. Pathogen effector proteins facilitate disease but can become avirulence (Avr) factors when the host acquires discrete recognition capabilities that trigger immunity. The mechanisms that lead to changes to pathogen Avr factors that enable escape from host immunity are diverse, and include epigenetic switches that allow for reuse or recycling of effectors. This perspective outlines possibilities of how epigenetic control of Avr effector gene expression may have arisen and persisted in filamentous plant pathogens, and how it presents special problems for diagnosis and detection of specific pathogen strains or pathotypes.

Keywords: avirulence, detection, gene silencing, immunity, pathotype, virulence, R-gene, transposon

\section{INTRODUCTION}

In our material world, everyone faces the dilemma of what to keep and discard as priorities and needs change over time. It is an easy metaphor to compare the accumulation of possessions by a household to the accumulation of genes within a genome; however, the forces of natural selection are extemporaneous and cannot plan for the future. Nonetheless, the underlying molecular systems that continually edit a genome will themselves be affected by successes and failures that occur only after the passage of time. Genes and other genetic elements can be sorted, deleted, retained, and regulated within a genome in a way that maximizes survivorship in the future. This is the concept briefly explored here, using the example of effector proteins from filamentous plant pathogens that interact with host plant immune systems.

\section{WHY DO PATHOGENS HAVE Avr FACTORS?}

Plant pathogen effector proteins represent finely tuned instruments of infection that are crucial to the parasitic lifestyle (Hogenhout et al., 2009; Rovenich et al., 2014). Effectors establish conditions that permit pathogenic organisms to grow and reproduce on their hosts. But an asset can become a liability when host plant immune systems evolve recognition capabilities that home in on effectors as triggers to activate robust defense responses that arrest pathogen growth (Dangl et al., 2013). In such cases of effector triggered immunity (ETI), the pathogen effector responsible for host immune activation is known as an avirulence (Avr) factor (de Wit, 2007). Pathogen Avr factors always raise simplistic questions when they are introduced to students of plant pathology. Why do pathogens possess Avr factors, since they are self-defeating? Why haven't all the Avr factors been eliminated by natural selection? The answers of course hinge on the conditionality of ETI and on the utility of Avr factors in circumstances where they escape host immune recognition systems.

\section{GAIN OF VIRULENCE IS ESCAPE FROM IMMUNITY}

When a pathogen effector comes under host immune surveillance, the corresponding Avr gene needs to change in some way, so that the Avr factor no longer causes ETI, in order for the pathogen to grow and reproduce on hosts with the enhanced immune capability. The necessary gain of virulence changes will depend on how the host immune system interacts with the effector (Stergiopoulos and de Wit, 2009). Conventional mutations to Avr genes that result in gain of virulence are exceedingly diverse (de Wit et al., 2009; Takken and Rep, 2010; Valent and Khang, 2010; Ravensdale et al., 2011; Jiang and Tyler, 2012; Huang et al., 2014; Vleeshouwers and Oliver, 2014). Pseudogenization due to interruption of the Avr open reading frame and wholesale Avr gene losses are common. This observation points to the dispensability of individual Avr genes and suggests that pathogen effector arsenals have a built-in redundancy. Provided that an Avr factor is retained by some individuals within a pathogen population, subpopulations or lineages can apparently lose and recover Avr genes repeatedly, as circumstances warrant. For example, in an asexually recombining population of a fungal pathogen, deleted Avr genes can be regained from other members of the same population (Chuma et al., 2011). There are also numerous examples of gain of virulence changes to pathogen Avr genes that are accomplished without any nucleotide changes whatsoever occurring within the open reading frame (Kang et al., 2001; Shan et al., 2004; Qutob et al., 2009; Dou et al., 2010; Dong et al., 2011; Gilroy et al., 2011; Qutob et al., 2013; Ali et al., 2014; Na et al., 2014). This can occur by epiallelic variation or by conventional mutations to cis-elements or flanking sequences that provide regulatory control of Avr gene transcription or translation, or possibly by changes to trans-acting elements, such as transcription- or epigenetic-factors that control Avr gene expression.

\section{NATURALLY OCCURRING REVERSIBLE SYSTEMS FOR Avr EXPRESSION STATES}

Gain of virulence changes that leave the open reading frame of the Avr gene itself unchanged may be more easily reversible, should appropriate conditions occur for the re-deployment of an Avr allele that has been suppressed or wiped out of the population through a selective sweep. Epigenetic systems that 
regulate transcription offer powerful and versatile means for reversibly controlling effector gene expression states depending on environmental conditions. For example, experiments suggest that histone $\mathrm{H} 3$ lysine 9 ( $\mathrm{H} 3 \mathrm{~K} 9$ ) methylation plays an role in coordinating the expression of hundreds of effectors in a fungal plant pathogen (Soyer et al., 2014). Epigenetic control of effector genes could arise in various ways, such as by recruiting existing systems that regulate the transcription and proliferation of mobile genetic elements or transposons (Sacristan et al., 2009; Kasuga et al., 2012; Whisson et al., 2012). This model is illustrated in Figure 1. Ancient epigenetic systems that release and silence transposons are proposed to contribute to genome plasticity and to be vitally important to evolutionary adaptation (Fedoroff, 2012). Whole genome sequencing of filamentous plant pathogens has provided good examples demonstrating that effectors and other genes associated with pathogenicity, host-range, and virulence are often embedded in repetitive, transposon-rich segments (Tyler et al., 2006; Haas et al., 2009; Spanu et al., 2010). The positioning of effector genes in such regions is advantageous because it facilitates duplication, recombination, and mutational mechanisms that lead to variation and often underlie gain of virulence changes (Van de Wouw etal., 2010; Rouxel etal., 2011; Raffaele and Kamoun, 2012). The close association with transposons could have allowed effector genes to co-opt or capture epigenetic switches dedicated to regulating the mobile genetic elements (Vetukuri et al., 2013). There is also evidence indicating that epigenetic regulators themselves can be highly polymorphic and positioned in repetitive, transposon-rich segments, suggesting adaptive interplay between conventional- and epigenetic variations in plant pathogens (Raffaele et al., 2010).

Conceptually, the flexible nature of epigenetic control appears tailor-made for pathogen Avr effector genes, as illustrated in Figure 2. Spontaneous changes in Avr gene expression states have been experimentally observed ( $\mathrm{Na}$ et al., 2014) and could help to account for previous descriptions of variation in virulence of

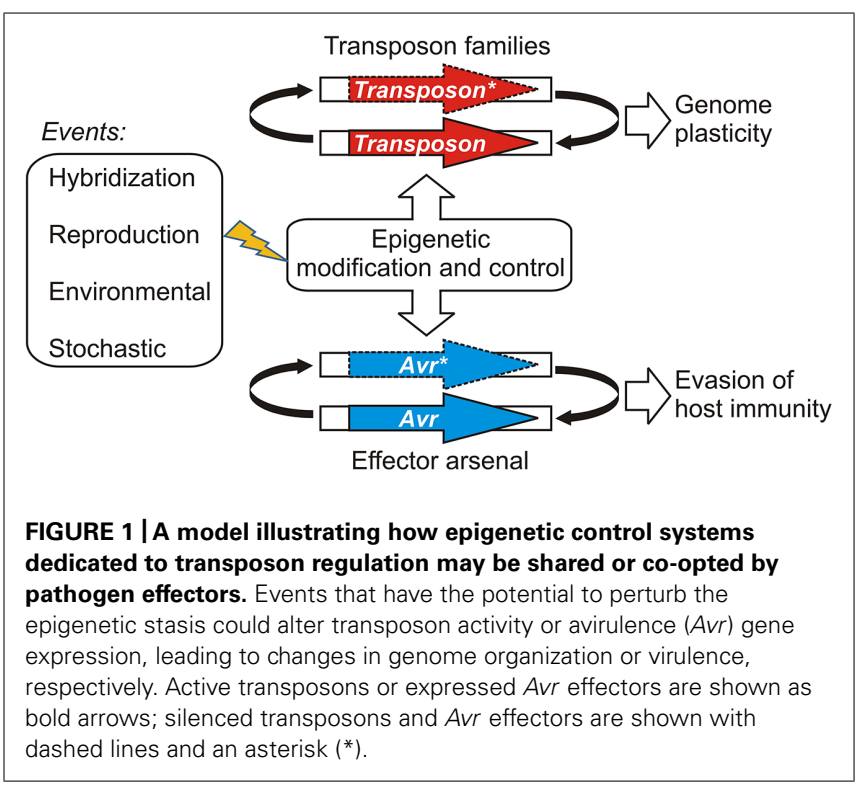



clonal isolates in the laboratory (Rutherford et al., 1985) or in the field (Goodwin et al., 1995; Hovmøller and Justesen, 2007). Historically, plant pathologists have always struggled to explain changes in virulence of pathogen populations, and have noted that as specific gain of virulence changes accumulate in a pathogen strain, it loses general fitness or aggressiveness (Van der Plank, 1968; Watson, 1970).

Epigenetic switching of expression allows the pathogen to respond successfully to new immune capabilities of the host while retaining Avr genes for future use, if necessary. For example, host immunity in natural or cultivated plant populations may change as a result of genetic drift or agronomic practices. An immune receptor encoded by a host resistance $(R)$ gene can be easily lost or mutated, or fall in to disuse, in the absence of any selective pressure or economic advantage, especially so if there is a fitness cost. The pathogen could also jump to a new host, or be introduced to a new environment, where the Avr factor does not face the challenge of host immune recognition. Under such circumstances, re-activating or recycling previous Avr effector genes could impart a fitness benefit that aids pathogen growth and reproduction.

\section{EPIALLELIC VARIATION OF Avr GENE EXPRESSION PRESENTS PRACTICAL PROBLEMS}

Most troublesome to plant breeders is that epigenetic variation in Avr gene expression allows pathogens to adapt rapidly and recycle effectors after a selective sweep imposed by cultivar specific R-gene deployment. Epiallelic variation of Avr effector gene expression also presents diagnostic and detection problems for plant pathologists aiming to develop pathotype-specific tests for better tracking, management, and control of plant disease causing organisms. This is significant because molecular tools are currently driving advances in plant breeding and pathogen diagnostics, as breeders, pathologists, inspectors, and regulators increasingly rely on genetic information for their decision making. Sequence data can be helpful in characterizing pathogen strains from the field and 
predicting the risk of $R$-gene failure (Van de Wouw and Howlett, 2012) but genetic tests based on DNA sequences do not have the capability to detect expression differences. Testing a gene expression state is more technically demanding and requires greater skill, time, and resources; it is not a test that is routinely performed by diagnostic laboratories. Perhaps inexpensive and efficient detection systems will be developed and applied to this problem in the future, such as for RNA molecules, or DNA or protein modifications that could underlie epigenetic variation. Until this occurs it does not seem likely that simple tests will be available for pathotyping strains that vary epigenetically in Avr gene expression. Traditional pathotyping relies on isolation, culturing, and phenotyping pathogen strains by inoculation on a set of plant lines carrying different $R$-genes. This demands considerable time and expertise, and requires plants, growth facilities, and other materials dedicated to each disease causing organism. The result is that strain pathotyping is usually done only by research laboratories that are specialized towards a particular organism or are well-versed in the proper bioassay.

\section{CONCLUSION}

This perspective introduces the concept of epigenetic variation of effector expression in plant pathogens. It is a newly discovered phenomenon that is still in the early stages of being characterized. Epigenetic variation contributes to phenotypic diversity and host adaptation and helps to explain how disease causing and invasive organisms rapidly adapt to changing host and environmental conditions (Kasuga and Gijzen, 2013). The prevalence of epigenetic variation, its mechanistic control, its relative importance to particular plant pathogen species, and its interplay with conventional genetic variation all require further work to define. Are the known and proposed examples of epigenetic variation within plant pathogens unusual and rare curiosities, or do they point to a more widespread biological phenomenon with evolutionary implications that have been long overlooked or undetected? Many scientists suspect the latter may be true, but it is a question that deserves a clear answer. There are potentially wide-ranging consequences affecting disease management and diagnostics that arise from epigenetic control of Avr genes and other host-range determinants. This should spur additional research in the area, which can only be helpful for controlling plant diseases that are damaging to crops, ornamental plants, and natural environments.

\section{ACKNOWLEDGMENT}

Support from Agriculture and Agri-Food Canada GRDI program is gratefully acknowledged.

\section{REFERENCES}

Ali, S., Laurie, J. D., Linning, R., Cervantes-Chavez, J. A., Gaudet, D., and Bakkeren, G. (2014). An immunity-triggering effector from the Barley smut fungus Ustilago hordei resides in an Ustilaginaceae-specific cluster bearing signs of transposable element-assisted evolution. PLoS Pathog. 10:e1004223. doi: 10.1371/journal.ppat.1004223

Chuma, I., Isobe, C., Hotta, Y., Ibaragi, K., Futamata, N., Kusaba, M., et al. (2011). Multiple translocation of the AVR-Pita effector gene among chromosomes of the rice blast fungus Magnaporthe oryzae and related species. PLoS Pathog 7:e1002147. doi: 10.1371/journal.ppat.1002147
Dangl, J. L., Horvath, D. M., and Staskawicz, B. J. (2013). Pivoting the plant immune system from dissection to deployment. Science 341, 746-751. doi: $10.1126 /$ science. 1236011

de Wit, P. J. (2007). How plants recognize pathogens and defend themselves. Cell Mol. Life Sci. 64, 2726-2732. doi: 10.1007/s00018-007-7284-7

de Wit, P. J., Mehrabi, R., Van den Burg, H. A., and Stergiopoulos, I. (2009). Fungal effector proteins: past, present and future. Mol. Plant Pathol. 10, 735-747. doi: 10.1111/j.1364-3703.2009.00591.x

Dong, S., Yu, D., Cui, L., Qutob, D., Tedman-Jones, J., Kale, S. D., et al. (2011). Sequence variants of the Phytophthora sojae RXLR effector Avr3a/5 are differentially recognized by Rps3a and Rps5 in soybean. PLoS ONE 6:e20172. doi: 10.1371/journal.pone.0020172

Dou, D., Kale, S. D., Liu, T., Tang, Q., Wang, X., Arredondo, F. D., et al. (2010). Different domains of Phytophthora sojae effector Avr4/6 are recognized by soybean resistance genes Rps4 and Rps6. Mol. Plant Microbe Interact. 23, 425-435. doi: 10.1094/MPMI-23-4-0425

Fedoroff, N. V. (2012). Presidential address. Transposable elements, epigenetics, and genome evolution. Science 338, 758-767. doi: 10.1126/science.338.6108.758

Gilroy, E. M., Breen, S., Whisson, S. C., Squires, J., Hein, I., Kaczmarek, M., et al. (2011). Presence/absence, differential expression and sequence polymorphisms between PiAVR2 and PiAVR2-like in Phytophthora infestans determine virulence on R2 plants. New Phytol. 191, 763-776. doi: 10.1111/j.1469-8137.2011.03736.x

Goodwin, S. B., Sujkowski, L. S., and Fry, W. E. (1995). Rapid evolution of pathogenicity within clonal lineages of the potato late blight disease fungus. Phytopathology 85, 669-676. doi: 10.1094/Phyto-85-669

Haas, B. J., Kamoun, S., Zody, M. C., Jiang, R. H., Handsaker, R. E., Cano, L. M., et al. (2009). Genome sequence and analysis of the Irish potato famine pathogen Phytophthora infestans. Nature 461, 393-398. doi: 10.1038/nature08358

Hogenhout, S. A., Van der Hoorn, R. A. L., Terauchi, R., and Kamoun, S. (2009). Emerging concepts in effector biology of plant-associated organisms. Mol. Plant Microbe Interact. 22, 115-122. doi: 10.1094/MPMI-22-2-0115

Hovmøller, M. S., and Justesen, A. F. (2007). Rates of evolution of avirulence phenotypes and DNA markers in a northwest European population of Puccinia striiformis f. sp. tritici. Mol. Ecol. 16, 4637-4647. doi: 10.1111/j.1365294X.2007.03513.x

Huang, J., Si, W., Deng, Q., Li, P., and Yang, S. (2014). Rapid evolution of avirulence genes in rice blast fungus Magnaporthe oryzae. BMC Genet. 15:45. doi: 10.1186/1471-2156-15-45

Jiang, R. H., and Tyler, B. M. (2012). "Mechanisms and evolution of virulence in oomycetes. Annu. Rev. Phytopathol. 50, 295-318. doi: 10.1146/annurev-phyto081211-172912

Kang, S., Lebrun, M. H., Farrall L., and Valent B. (2001). Gain of virulence caused by insertion of a Pot3 transposon in a Magnaporthe grisea avirulence gene. Mol. Plant Microbe Interact. 14, 671-674. doi: 10.1094/MPMI.2001. 14.5.671

Kasuga, T., and Gijzen, M. (2013). Epigenetics and the evolution of virulence. Trends Microbiol. 21, 575-582. doi: 10.1016/j.tim.2013.09.003

Kasuga, T., Kozanitas, M., Bui, M., Huberli, D., Rizzo, D. M., and Garbelotto, M. (2012). Phenotypic diversification is associated with host-induced transposon derepression in the sudden oak death pathogen Phytophthora ramorum. PLoS ONE 7:e34728. doi: 10.1371/journal.pone.0034728

Na, R., Yu, D., Chapman, B. P., Zhang, Y., Kuflu, K., Austin, R., et al. (2014). Genome re-sequencing and functional analysis places the Phytophthora sojae avirulence genes Avrlc and Avrla in a tandem repeat at a single locus. PLoS ONE 9:e89738. doi: 10.1371/journal.pone.0089738

Qutob, D., Patrick Chapman, B., and Gijzen, M. (2013). Transgenerational gene silencing causes gain of virulence in a plant pathogen. Nat. Commun. 4, 1349. doi: 10.1038/ncomms2354

Qutob, D., Tedman-Jones, J., Dong, S., Kuflu, K., Pham, H., Wang, Y., et al. (2009). Copy number variation and transcriptional polymorphisms of Phytophthora sojae RXLR effector genes Avrla and Avr3a. PLoS ONE 4:e5066. doi: 10.1371/journal.pone.0005066

Raffaele, S., Farrer, R. A., Cano, L. M., Studholme, D. J., MacLean, D., Thines, M., et al. (2010). Genome evolution following host jumps in the Irish potato famine pathogen lineage. Science 330, 1540-1543. doi: 10.1126/science. 1193070

Raffaele, S., and Kamoun, S. (2012). Genome evolution in filamentous plant pathogens: why bigger can be better. Nat. Rev. Microbiol. 10, 417-430. doi: 10.1038/nrmicro2790 
Ravensdale, M., Nemri, A., Thrall, P. H., Ellis, J. G., and Dodds, P. N. (2011). Co-evolutionary interactions between host resistance and pathogen effector genes in flax rust disease. Mol. Plant Pathol. 12, 93-102. doi: 10.1111/j.13643703.2010.00657.x

Rouxel, T., Grandaubert, J., Hane, J. K., Hoede, C., van de Wouw, A. P., Couloux, A., et al. (2011). Effector diversification within compartments of the Leptosphaeria maculans genome affected by Repeat-Induced Point mutations. Nat. Commun. 2, 202. doi: 10.1038/ncomms1189

Rovenich, H., Boshoven, J. C., and Thomma, B. P. (2014). Filamentous pathogen effector functions: of pathogens, hosts and microbiomes. Curr. Opin. Plant Biol. 20C, 96-103. doi: 10.1016/j.pbi.2014.05.001

Rutherford, F. S., Ward, E. W. B., and Buzzell, R. I. (1985). Variation in virulence in successive single-zoospore propagations of Phytophthora megasperma f.sp. glycinea. Phytopathology 75, 371-374. doi: 10.1094/Phyto75-371

Sacristan, S., Vigouroux, M., Pedersen, C., Skamnioti, P., Thordal-Christensen, H., Micali, C., et al. (2009). Coevolution between a family of parasite virulence effectors and a class of LINE-1 retrotransposons. PLoS ONE 4:e7463. doi: 10.1371/journal.pone.0007463

Shan, W. X., Cao, M., Dan, L. U., and Tyler, B. M. (2004). The Avrlb locus of Phytophthora sojae encodes an elicitor and a regulator required for avirulence on soybean plants carrying resistance gene Rps1b. Mol. Plant Microbe Interact. 17, 394-403. doi: 10.1094/MPMI.2004.17.4.394

Soyer, J. L., El Ghalid, M., Glaser, N., Ollivier, B., Linglin, J., Grandaubert, J., et al. (2014). Epigenetic control of effector gene expression in the plant pathogenic fungus Leptosphaeria maculans. PLoS Genet. 10:e1004227. doi: 10.1371/journal.pgen.1004227

Spanu, P. D., Abbott, J. C., Amselem, J., Burgis, T. A., Soanes, D. M., Stuber, K., etal. (2010). Genome expansion and gene loss in powdery mildew fungi reveal tradeoffs in extreme parasitism. Science 330, 1543-1546. doi: $10.1126 /$ science. 1194573

Stergiopoulos, I., and de Wit, P. J. (2009). Fungal effector proteins. Annu. Rev. Phytopathol. 47, 233-263. doi: 10.1146/annurev.phyto.112408.132637

Takken, F., and Rep, M. (2010). The arms race between tomato and Fusarium oxysporum. Mol. Plant Pathol. 11, 309-314. doi: 10.1111/j.1364-3703.2009.0 0605.x

Tyler, B. M., Tripathy, S., Zhang, X. M., Dehal, P., Jiang, R. H. Y., Aerts, A. et al. (2006). Phytophthora genome sequences uncover evolutionary origins and mechanisms of pathogenesis. Science 313, 1261-1266. doi: 10.1126/science. 1128796
Valent, B., and Khang, C. H. (2010). Recent advances in rice blast effector research. Curr. Opin. Plant Biol. 13, 434-441. doi: 10.1016/j.pbi.2010.04.012

Van de Wouw, A. P., Cozijnsen, A. J., Hane, J. K., Brunner, P. C., McDonald, B. A., Oliver, R. P., et al. (2010). Evolution of linked avirulence effectors in Leptosphaeria maculans is affected by genomic environment and exposure to resistance genes in host plants. PLoS Pathog. 6:e1001180. doi: 10.1371/journal.ppat. 1001180

Van de Wouw, A. P., and Howlett, B. J. (2012). Estimating frequencies of virulent isolates in field populations of a plant pathogenic fungus, Leptosphaeria maculans, using high-throughput pyrosequencing. J. Appl. Microbiol. 113, 1145-1153. doi: 10.1111/j.1365-2672.2012.05413.x

Van der Plank, J. E. (1968). Disease Resistance in Plants. New York: Academic Press.

Vetukuri, R. R., Asman, A. K., Jahan, S. N., Avrova, A. O., Whisson, S. C., and Dixelius, C. (2013). Phenotypic diversification by gene silencing in Phytophthora plant pathogens. Commun. Integr. Biol. 6:e25890. doi: 10.4161/cib.25890

Vleeshouwers, V. G., and Oliver, R. P. (2014). Effectors as tools in disease resistance breeding against biotrophic, hemibiotrophic, and necrotrophic plant pathogens. Mol. Plant Microbe Interact. 27, 196-206. doi: 10.1094/MPMI-10-13-0313-IA

Watson, I. A. (1970). Changes in virulence and population shifts in plant pathogens. Annu. Rev. Phytopathol. 8, 209-230. doi: 10.1146/annurev.py.08.090170.001233

Whisson, S., Vetukuri, R., Avrova, A., and Dixelius, C. (2012). Can silencing of transposons contribute to variation in effector gene expression in Phytophthora infestans? Mob. Genet. Elements 2, 110-114. doi: 10.4161/mge.20265

Conflict of Interest Statement: The authors declare that the research was conducted in the absence of any commercial or financial relationships that could be construed as a potential conflict of interest.

Received: 08 September 2014; paper pending published: 05 October 2014; accepted: 27 October 2014; published online: 12 November 2014.

Citation: Gijzen M, Ishmael C and Shrestha SD (2014) Epigenetic control of effectors in plant pathogens. Front. Plant Sci. 5:638. doi: 10.3389/fpls.2014.00638

This article was submitted to Plant Genetics and Genomics, a section of the journal Frontiers in Plant Science.

Copyright $\odot 2014$ Gijzen, Ishmael and Shrestha. This is an open-access article distributed under the terms of the Creative Commons Attribution License (CC BY). The use, distribution or reproduction in other forums is permitted, provided the original author(s) or licensor are credited and that the original publication in this journal is cited, in accordance with accepted academic practice. No use, distribution or reproduction is permitted which does not comply with these terms. 